\title{
Risk factors of allergic rhinitis: genetic or environmental?
}

\author{
De-Yun Wang \\ Department of Otolaryngology, \\ Faculty of Medicine, National \\ University of Singapore, Singapore
}

\begin{abstract}
Allergic diseases such as allergic rhinitis represent a global health problem, affecting $10 \%-25 \%$ of the world population. There is clear evidence to support the concept that allergic diseases are influenced by genetic predisposition and environmental exposure. Polymorphisms of candidate genes have been associated with clinical expression of these diseases. However, characterization of these susceptibility markers in discriminating an "allergic individual" from the general population has not yet been achieved, and the value of how this genetic insight leading to recognition of specific subtypes of these disorders still needs to be confirmed. Environmental factors (eg, air pollution and bacterial/viral infection) also play an important role in the development of the diseases. A number of epidemiologic studies have supported the "hygiene hypothesis", which is based on the observations that Th1 responses induced by microbial stimulation can counterbalance allergen-induced Th2 responses. Future studies are needed to identify the key genes or their haplotypes for atopic phenotypes and to investigate the interactions between genetic and environmental factors that influence the complex trait of allergic diseases. This will help us to further understand the etiology of the diseases and develop new avenues for genetically oriented diagnosis and more effective measures of prevention and intervention.
\end{abstract}

Keywords: allergic rhinitis, genetic predisposition, environmental factors

\section{Introduction}

Allergic rhinitis (AR) is a common manifestation of allergic diseases affecting approximately $10 \%-25 \%$ of the world population (Bousquet et al 2001). The symptoms of AR include rhinorrhea, nasal obstruction, nasal itching, and sneezing. The symptoms are reversible and are caused spontaneously by exposure to allergens and triggering factors or whilst under treatment. Allergic rhinitis is a major airway disease, which causes morbidity and significantly impairs a patient's ability to function and their quality of life. It is also associated with other conditions such as asthma, sinusitis, anosmia, otitis media, nasal polyps, lower airway infection, and even dental malocclusion (International Rhinitis Management Working Group 1994; Spector 1997; Canonica et al 1998; Apter et al 1999).

Allergic rhinitis is caused frequently by exposure to perennial or seasonal allergens that exist in our indoor and outdoor environment. Among the most common allergens, pollens (grass, trees, and weeds) are the predominant causes of seasonal allergic rhinitis. House dust mites, pets, and molds are the major causes of perennial allergic rhinitis. However, in tropical and subtropical areas pollen may become a perennial allergen. Recently, the document Allergic rhinitis and its impact on asthma (ARIA), which was developed in collaboration with the WHO, has recommended to replace the old terms "seasonal" and "perennial" rhinitis by "intermittent allergic rhinitis" and "persistent allergic rhinitis", respectively (Bousquet et al 2001). 
IgE-mediated immunologic mechanisms are known to play a key role by triggering the release of mediators that are responsible for allergic symptoms. Transendothelial migration of inflammatory cells and their activation within the reactive tissue are characteristic features, which represent the result of a complex network of interactions between various mediators, cytokines, chemokines, and adhesion molecules. It has been suggested that an imbalance of Th1 and Th2 cells, especially Th2 cells, plays an important role in regulating IgE synthesis and cell recruitment at the sites of inflammation. In allergic rhinitis, many studies have demonstrated that mucosal inflammation is characterized by the tissue infiltration of T-lymphocytes (CD4+ T cells and CD25+ T cells) in the submucosa and epithelium (Durham et al 1992; Varney et al 1992).

During past decades, the prevalence of allergic rhinitis has increased, especially in developed and industrialized countries. The complete etiology for the development and expression of atopic disease is not yet understood. Several putative factors have been proposed such as changes in lifestyle; increase in exposure to allergens, pollution, and irritants (smoke, gas, etc); changes in diet responsible for the diminution of protective nutrient intake; decrease in infections; and stress (Bousquet 2001). Thus, interaction between environmental factors and individual susceptibility is essential.

This paper reviews recent understanding of the pathogenic mechanisms, which are influenced by a complex immune procedure, including interaction of multiple genes, interaction of environmental and genetic factors, and population heterogeneity. Understanding the etiology of allergic rhinitics will lead to the development of genetically oriented diagnosis and more effective environmental control measures.

\section{The genetic characters of allergic rhinitis}

A genetic background in terms of a family history of atopic disease has been the strongest risk factor for the development of allergic symptoms, irrespective of the varying prevalence and environmental risk factors in different societies. The most convincing evidence for genetic effect in the development of atopy is derived from twin studies. The earliest study by Edfors-Lubs, dating back to 1971, showed the hereditary character of allergic rhinitis in twins (Edfors-Lubs 1971). Later, Hopp and colleagues (1984) found a greater concordance of allergic manifestations in monozygotic than dizygotic twins in terms of correlation coefficient of serum total $\operatorname{IgE}$ ( 0.82 vs 0.52$)$, skin test response $(0.82$ vs 0.46$)$, and bronchial reactivity to inhaled methacholine (0.67 vs 0.34 ).

Atopy is a key condition in the development of allergic diseases, particularly with the IgE-mediated mechanism. It is a disorder with strong familial tendency, usually starting in childhood or adolescence, when patients become sensitized and produce $\operatorname{IgE}$ antibodies in response to ordinary allergens (Johannson et al 2004). The complex mechanisms of inheritance, from genetic predisposition of atopy to atopic (allergic) diseases, are still incompletely understood (Figure 1). Some studies suggest that the pathogenesis of allergic diseases is complex and may be caused by a contribution of genetic and environmental factors, especially at the stage of allergen sensitization.

In the area of human genetic study, many candidate genes have been identified using position cloning and linkage analysis techniques (Moffatt and Cookson 1999; Peden 2002; Toda and Ono 2002). The genome-wide search approach has shown an association between certain phenotypes of allergic diseases (rhinitis and/or asthma) with markers on more than 14 pairs of chromosomes (ie, chromosome 1, 2, 3, 5, 6, 7, 9, 11, 12, 13, 14, 16, 17, 19, and more). Some of these genes are involved in the specific immune response (ie, HLA-D, TCR, CD14, toll-like receptor, STAT6) and Th1/Th2 cell differentiation; others are genes coding the (total) IgE response or functions of the IgE receptors (ie, IL-4, IL-4R, FceRI $\beta$, FcepsilonRI) and genes involved in the inflammatory process (TNF- $\gamma$, IFN- $\gamma$, IL-3) (Cookson et al 1989; Marsh et al 1994; Barnes et al 1996; Noguchi et al 1997, 1998b; Baldini et al 1999; Deichmann et al 1999; Shek et al 2001; Nisiyama et al 2004; Park et al 2004; Weidinger et al 2004; Pykalainen et al 2005). However, studies on association of allergic manifestations with candidate gene polymorphisms have yielded conflicting results. Limited sample size with insufficient statistical power is always a critical methodological issue, which is often neglected in some of the case-control or populationbased studies.

Various ethnic background influences the outcome of genetic epidemiological studies. There is the presence of a large difference in allele distribution of several allergyrelated gene (eg, IL-4 and IL-4-R gene) polymorphisms among various ethnic populations. For the IL-4 gene, a C to T polymorphism at IL-4/-590 was reported to be associated with serum total IgE level (Rosenwasser et al 1995), development of asthma (Noguchi et al 1998a), and atopic dermatitis (Kawashima et al 1998). It seems that $\mathrm{T}$ allele 


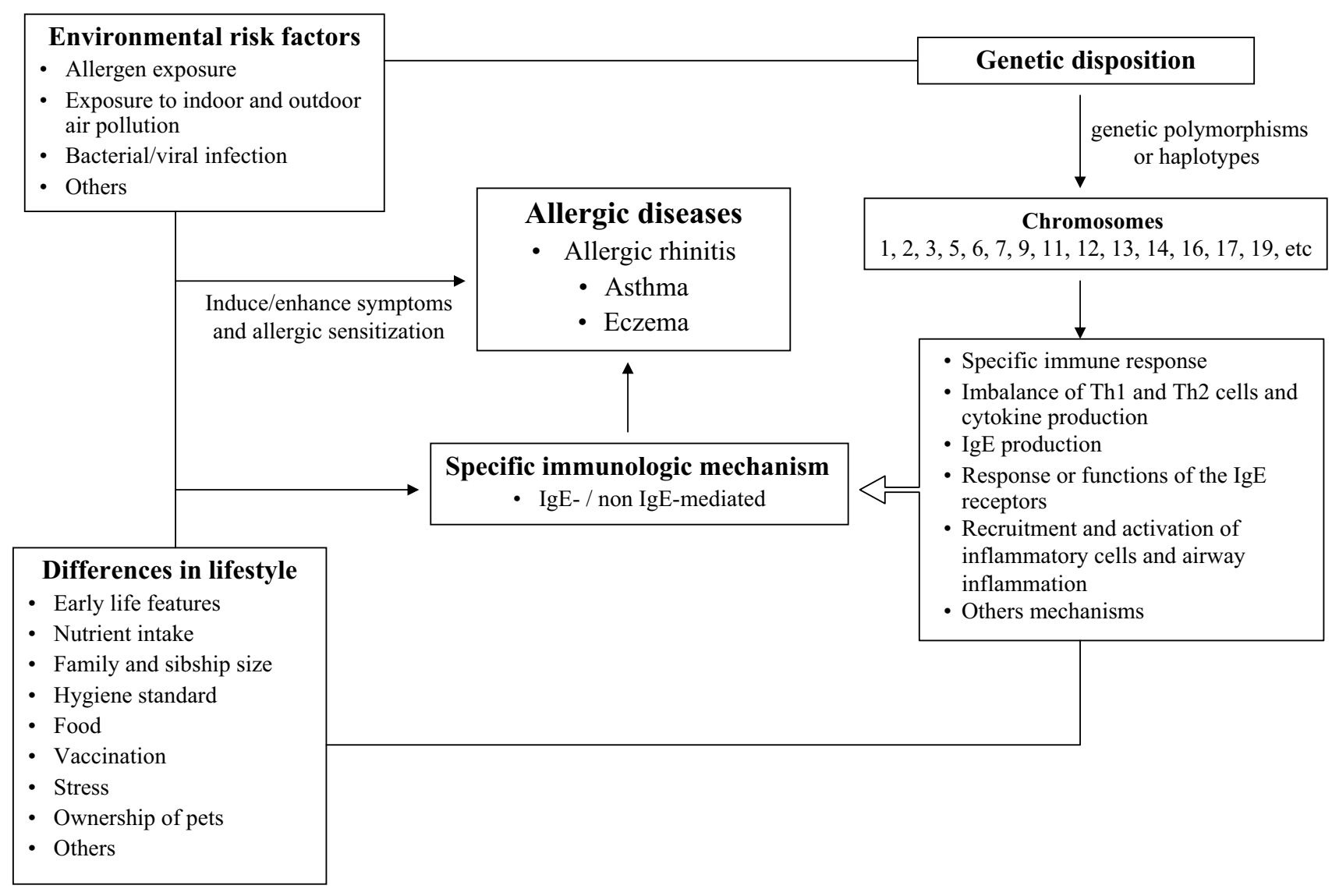

Figure I Risk factors of allergic diseases.

frequency is less frequent in Caucasians than Asian populations with a difference of up to 6-fold. The $\mathrm{T}$ allele is common (70\%-73\%) in Japanese (Noguchi et al 1998b), but less common (12.5\%) in Germans (Kabesch et al 2003). Our recent study showed a significant difference of $\mathrm{T}$ allele frequency at IL-4/-590 among Chinese (non-atopic 90.2\% and atopic $87.3 \%$ ), Malays (non-atopic $83.3 \%$ and atopic $77.1 \%$ ), and Asian Indians (non-atopic 38.1\% and atopic $44.1 \%$ ) (Unpublished data). For the IL-4R, the association of atopy with a gain-of-function mutation in the $\alpha$ subunit of the IL-4 receptor (Q576R) was found to be a critical condition of atopy (Hershey et al 1997). On the contrary, a study performed in Singapore has reported a significant ethnic variation of this polymorphism among Chinese, Malays, and Indians, and no association was found between this polymorphism and atopy in all three ethnic groups (Tan et al 1999).

To date, neither fine mapping nor particular genetic polymorphisms have been confirmed to be a critical condition in the development or clinical manifestations of allergic diseases. It is not surprising since predisposition to atopy is influenced by a complex immune procedure, including interactions of multiple genes, interaction of environmental and genetic factors, and population heterogeneity. Future studies are needed to identify the key genes or the joint effect of several susceptibility genes (haplotypes) that leads to allergic phenotypes. Furthermore, statistical methods for discovering sets of susceptible genes and environmental factors, as well as systematic verifications of the gene-environment-disease network would have a great impact on future genetic epidemiological studies (Hoh and Ott 2004).

\section{Environmental factors}

Environmental factors such as increased air pollution, changed lifestyle, and decrease in bacterial/viral infection are frequently quoted as adjuvant factors for allergic sensitization and possible causes of the increased prevalence.

\section{Protective effect of infections on atopy - "hygiene hypothesis"}

During the past decade, the simulative question of why atopic diseases are increasing in prevalence, which is inversely proportional to the prevalence of communicable diseases, is due to the improvement of healthcare policy 
and hygiene standard, especially in developed countries. The so-called hygiene hypothesis of allergy was first suggested by Strachan (1989), who noted that the risk of developing allergies and asthma is inversely related to the number of children in the family. This effect has since been confirmed using various markers of infectious burden such as number of older siblings (von Mutius et al 1994a; Jarvis et al 1997; Bodner et al 1998), attendance at day care facilities (Krämer et al 1998), positive serology to orofecal infections (Matricardi et al 1997, 2000), and regular contact with farm animals before the age of 7 years (Radon et al 2004).

To explain the hygiene hypothesis requires an appreciation of the developing immune system. $\mathrm{T}$ helper cell (Th2)-like cytokines (eg, IL-4, IL-5, and IL-13) produced in the uterine environment induce similar Th2like responses in the immature immune system of the newborn, which increases the likelihood that postnatal (and possibly even prenatal) exposure to allergens leading to production of allergen-specific IgE and eosinophilic inflammation (Warner et al 1998). According to the hygiene hypothesis, infections with viruses and perhaps other intracellular organisms also influence the developing immune system: the T-cell responses to these infections generate Th1-like cytokines such as IL-12 and IFN- $\gamma$ that down-regulate $\mathrm{Th} 2$ responses. Thus, the core of the hygiene hypothesis is based on the observations that Th1 responses induced by microbial stimulation can counterbalance allergen-induced Th2 responses. According to the hypothesis of "endotoxin switch", a dose-dependent relationship exists between environmental exposure to bacterial products and the outcome of the immune response. The quantity of environmental endotoxin may also affect the balance of the Th1/Th2 cytokine level. It has been suggested that repeated viral infections other than lower respiratory tract infections early in life may stimulate the immature immune system towards the Th1 phenotype, thereby reducing the risk for the development of asthma up to school age (Illi et al 2001). The underlying mechanisms of these protective immunologic effects are still unclear.

Which environmental or microbial factors are the culprits for atopic manifestation? It should not be assumed that all infectious diseases have the same effects on the development or clinical manifestation of allergic diseases. It is known that lower respiratory tract infections including respiratory syncytial virus bronchiolitis, pneumonia, perhaps pertussis, and measles in childhood may increase the subsequent risk of childhood asthma without modifying the likelihood of sensitization to allergens (Gern and Weiss 2000). A larger Finish population study $(\mathrm{n}=517910)$ showed a strong positive association between measles and atopic manifestations, which does not support the hypothesis that experiencing natural measles infection offers protection against atopic diseases (Paunio et al 2000).

More work is needed in the area of longitudinal epidemiologic studies to evaluate the effects of childhood infections (eg, viral and bacterial infections) on the development of the immune system and pathophysiology of allergic diseases. The challenges for future studies include identification of those factors that confer the protection proposed by the hygiene hypothesis, and, if possible, to find strategies to modify the environment without causing harm to susceptible individuals (Eder and von Mutius 2004).

\section{Air pollution}

In addition to previously described allergens, exposure to high levels of pollutants including oxides of nitrogen, ozone, sulfur dioxide, black smoke-large particulate matter, small particulates, carbon monoxide, and volatile organic compounds have been considered as important contributing factors in both exacerbation and etiology of allergic airway diseases (Utell and Samet 1993; Devalia et al 1994; Krishna et al 1995).

It is still not clear whether the increasing prevalence of allergic diseases is distinctly different between the areas with higher or lower degrees of air pollution. The quantity and types of pollutants also influence the development of allergic disease. This has already been explained by an epidemiological study performed in two cities of Germany. Von Mutius et al (1994b) have studied a total of 7653 children in Munich $(n=5030)$ and Leipzig $(n=2623)$. In Leipzig, there was a considerably higher degree of air pollution, with sulfur dioxide produced by coal, while an "automobile type" of pollution was found in Munich. The prevalence rates of allergic rhinitis, asthma, and positive skin tests to aeroallergens were significantly lower in Leipzig $(2.7 \%$, $3.9 \%$, and $18.2 \%$ ) than in Munich (8.6\%, 5.9\%, and 36.7\%). Therefore, it was suggested that an effective pollution control policy will require an understanding of how measures to alter emissions from different sources influence personal exposure, and hence health outcomes (Ashmore 1995).

Air pollution certainly plays an important part, if not a pivotal role, in the pathogenesis of allergic and respiratory diseases. Some pollutants can either impair defense mechanisms in the airways rendering them more susceptible 
to viral and/or bacterial infection, or cause an immunological toxicity in the airways (Krishna et al 1995). Pollutants may also play a direct or indirect role in the pathophysiology and the development of allergic diseases (Cookson et al 1989; von Mutius et al 1994a; Hershey et al 1997; Matricardi et al 1997; Jarvis et al 1997; Bodner et al 1998; Krämer et al 1998; Shek et al 2001; Riedl and Diaz-Sanchez 2005) (Figure 2). More work is needed to identify which pollutants have an impact on human health and in which subgroups, and the mechanism for disease development. This will need to include the pathways of chemical, molecular, and cellular interactions. A more powerful epidemiological study must be performed on the basis of prospective settings in several regions, and with unique investigational criteria to assess the prevalence and severity of allergic disease.

\section{Control measures for indoor allergens}

Exposure of indoor allergens in our house environment is a common cause of perennial allergic rhinitis. Young children especially, spend most of their time inside the house. It is true that when a high concentration of one or more allergens is present in the house, the risk of allergenic sensitization in the early stages of life will increase consequently. In highrisk newborns, prenatal exposure to mite allergens from dust of the living room and the maternal mattress was found to be associated with total serum IgE at birth (Schonberger et al 2005).

\section{House dust}

House dust is a heterogenous mixture, which varies according to region and household. It consists of various allergenic substances, consisting primarily of somatic and metabolic allergens of mites and secondarily of allergens derived from domestic animals, human skin scales, domestic insects such as cockroaches, and endotoxin of gram-negative bacteria. In addition, fungal spores or mycelia and other products of animal or vegetable origin such as feathers, wool, and natural fibers may be sources of dust allergens.

Endotoxin, a component of the cell wall of gram-negative bacteria, is a potent proinflammatory agent commonly found in house dust. Exposure to endotoxin will induce an inflammation of the airways, characterized by a neutrophil invasion, irritation on the mucus membranes, and restricted airway diameter (Michel et al 1991, 2001). These effects are undoubtedly an enhancing factor for the severity of established allergic inflammation in rhinitis and asthma. It has been postulated that exposure to endotoxin at a critical time might shift the developing immune system to a predominantly Th1-type (increasing IFN- $\gamma$ and IL-12 productions) responsiveness, thus protecting against asthma and allergies (Martinez and Holt 1999). Further studies are still needed to determine the duration and dose-related effectiveness of endotoxin on Th1 cell polarization in terms of allergen sensitization and the existence of allergic inflammation in allergic rhinitis or asthma patients.

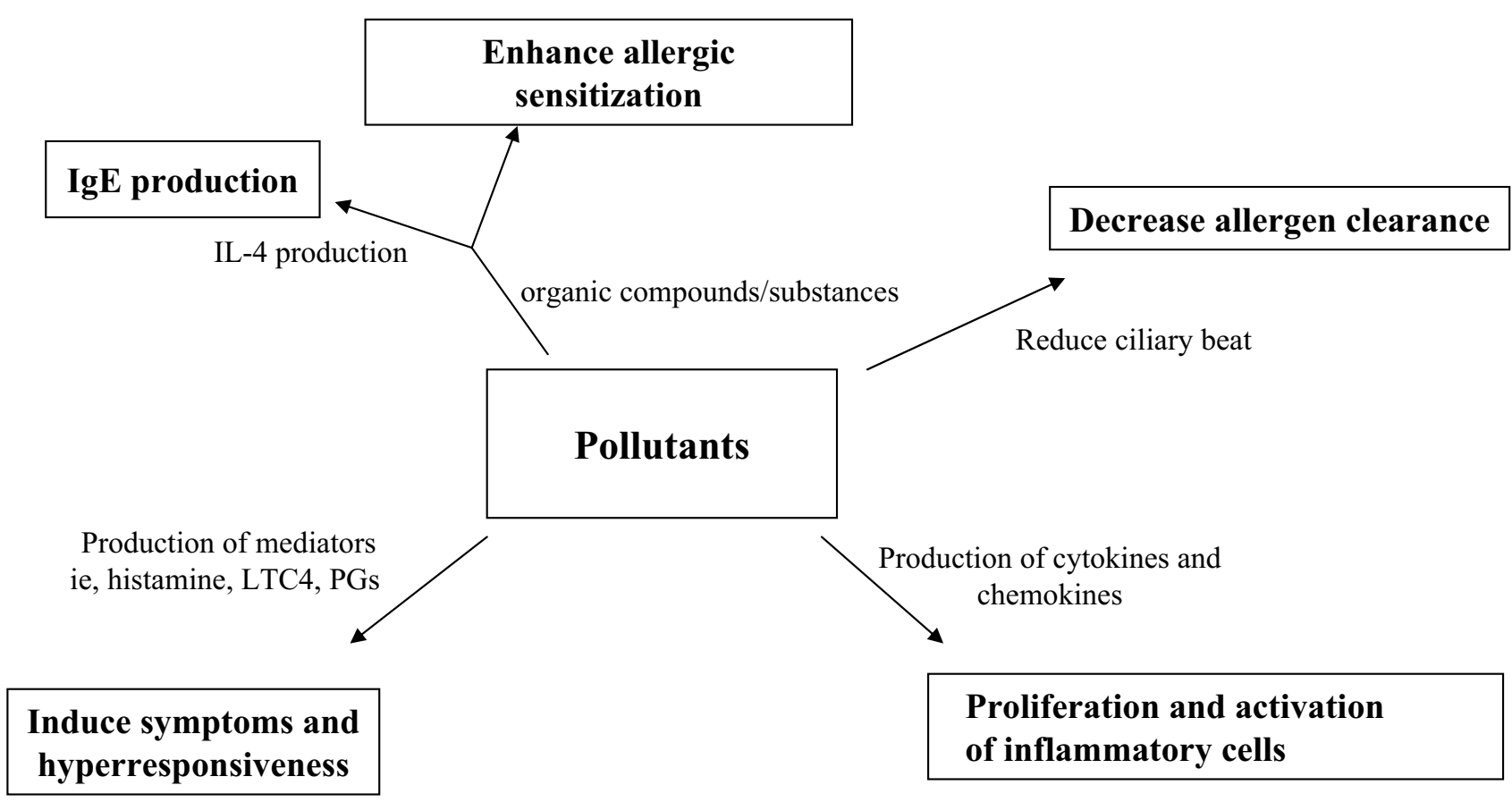

Figure 2 Possible effects of air pollution in allergic diseases. 
Muramic acid, a constituent of peptidoglycant in gramnegative and gram-positive bacteria in the environment, was suggested to be an additional marker of microbial exposure (van Strien et al 2004). A recent study was conducted on 553 farm and non-farm school children from Austria, Switzerland, and Germany. Their mattress dust muramic acid concentrations were determined and their health condition was assessed by using IgE measurements and questionnaire information. The muramic acid concentration was found to be significantly higher in dust from farm children's mattresses than in dust from non-farm children's mattresses ( $157 \mathrm{ng} / \mathrm{mg}$ vs $131 \mathrm{ng} / \mathrm{mg}$ ). Interestingly, children with higher mattress dust muramic acid concentrations had a significantly lower prevalence of wheezing regardless of farming status and endotoxin exposure (van Strien et al 2004).

\section{House dust mites}

House-dust mites (HDM) are the most common indoor allergens for allergic diseases such as allergic rhinitis and asthma. International studies have demonstrated that Dermatophagoides pteronyssinus (Der p), Dermatophagoides farinae (Derf) are the most common mite species worldwide (Bousquet et al 2001). In the tropics, Blomia tropicalis (B. tropicalis), another dust mite species, was found to be the most prevalent domestic mite (Zhang et al 1997; Wang et al 2003; Fernandez-Caldas and Lockey 2004). HDM are commonly found in association with bedding products, carpets, curtains, and fabric products. HDM hypersensitivity is strongly associated with persistent allergic rhinitis (PAR). Allergen avoidance, including house dust mites, is recommended to be an integral part of a management strategy for allergic rhinitis and asthma (Bousquet et al 2001).

The real challenge is to create a low allergen environment in patients' homes, and unfortunately, the majority of single interventions have failed to achieve a sufficient reduction in allergen load leading to a clinical improvement (Bousquet et al 2001). It is possible to reduce the concentration of house dust mites either by chemicals (tannic acid or solidified benzyl benzoate) or bedding encasings. House dust mite encasement products such as pillow and mattress covers are widely available for sale. Reimbursement from insurance companies for the purchase of such products in the United States is estimated at $\$ 42$ million in 2001 (Terrehorst et al 2003). Although laboratory studies have demonstrated the high filtering capabilities of these barrier products, surprisingly, few clinical trials studies have been done to date reporting the clinical efficacy of such prevention methods (Sheikh and Huwitz 2001). A multicentered, randomized, placebo-controlled study has been done so far to evaluate the efficacy of HDM impermeable bedding covers in the bedrooms of patients with allergic rhinitis, showing no significant improvement on clinical symptoms between treatment and control groups (Terrehorst et al 2003). This may be due to the high HDM load from other non-bedding products common in the home environment that may confound the results of the study.

It is commonly understood that exposure to HDM allergen in infancy increases the risk of developing asthma. However, a recent study was unable to find any relationship between the level of HDM allergen exposure in children's bedrooms in early childhood and development of bronchial hyperresponsiveness or physician-diagnosed asthma by age 6-7 years (Carter et al 2003). Another study was performed to compare the association between dust mite allergen level and asthma symptom prevalence across multiple countries in the Asia-Pacific region. Among children aged 6-7 years, neither allergen (Der $\mathrm{p} 1$ and Der $\mathrm{f} 1$ ) was related to asthmatic symptoms or severity prevalence (Wickens et al 2004). To address this conflicting issue, one needs sensitive measures to assess quantitatively and qualitatively the HDM exposure, as well as the exposure to other adjuvant factors in the home.

The relationships between house and household characteristics and allergen concentrations in both air and dust were complex (Peterson et al 2003). The concentrations of Der $\mathrm{f} 1$ in dust increased with increasing number of residents and relative humidity and declined when forced air heating was used. Dust concentrations of Der p 1 were lower in new homes and during forced air heating use but higher with higher relative humidity and in the presence of dogs. A study was performed to compare indoor allergens (Der p 1 and Der f 1) and endotoxin levels between urban and rural settings as important determinants for asthma and atopy in children. The results showed that indoor environmental factors such as dampness seemed to be important determinants for allergen and endotoxin, but living habits such as lack of mattress cover appeared unimportant (Wickens et al 2004).

In the tropics, the majority of allergic rhinitis is persistent in nature (Wang et al 2002). The year-round warm and humid climate is conducive to the proliferation of dust mites and molds, two of the most common aeroallergens implicated in persistent allergic rhinitis (Wang et al 2003). As patients with persistent allergic rhinitis are often symptomatic throughout the year and need long-term control of HDM 
exposure, ensuring compliance is essential. It is recommended that educational programs be implemented for physicians and patients as to the most effective therapeutic strategies leading to optimal outcomes (Wang et al 2004).

\section{Ownership of pets}

Pet ownership was found to markedly increase the risk of sensitization to pets (Al-Mousawi et al 2004). The prevalence of asthma, rhinitis, and skin allergy was significantly more common in families with animals than in those without (Bener et al 2004). The secretary proteins from a large number of animals carry or contain powerful allergens capable of causing severe hypersensitivity reactions. Cats and dogs are the main culprits particularly if they are allowed to enter and remain in the bedroom. Allergic rhinitis and asthma are common clinical manifestations of allergies to animals. Therefore, removal of the pet (cat or dog) from the home is still recommended for sensitized patients with ongoing allergic diseases.

The major cat allergen (Fel d 1) is a glycoprotein that is transported in the air by particles smaller than $2.5 \mu \mathrm{m}$ (Luczynska et al 1990), and these particles can remain airborne for long periods. They are also adherent, contaminating an entire environment for weeks or months after cessation of allergen exposure (Wood et al). A typical example is that allergens adherent to the clothing of people who have cats at home can trigger allergic reactions in sensitized individuals. It makes avoidance and prevention by sensitized individuals much more difficult, requiring public cooperation and awareness. It has been suggested in almost all clinical guidelines for sensitized patients with allergic rhinitis and/or asthma that pets (ie, cats and dogs) should be removed and to also carefully vacuum clean all carpets, mattresses, and upholstered furniture.

During the last few years, data of several epidemiologic studies have challenged the conventional understanding for pet avoidance in sensitized patients. Thus, the role of pet keeping during infancy for the development of allergy and asthma remains controversial. It was found that early exposure to a furry animal at home would lead to tolerance and reduced asthma at school age (Hesselmar et al 1999). A recent cohort study in Sweden with 1228 infants who were born over a 1-year period was investigated by questionnaires, and 817 of the children were skin prick tested both at age 1 and 4 years (Sandin et al 2004). The results showed that pet keeping during the first year of life was not associated with an increased risk of atopy at 4 years of age, although a positive skin prick test to cat was more common at 1 year.
These findings may even suggest that dog keeping during the first year of life might provide some protection from pollen allergy and late-onset wheezing and increase the risk of early-onset transient wheezing in children with heredity for asthma.

A wide range of allergens have been associated with allergic diseases. Total allergen avoidance appears to be effective (eg, symptom-free patients outside the pollen season or occupational exposure). However, patients are often sensitized to many allergens and the degree of exposure varies within indoor and outdoor environments. Moreover, the magnitude of reduction of allergen load needed to reduce symptoms is still unclear. However, it is clear that allergen exposure leads to symptoms. Thus, avoidance measures are still recommended but more research is strongly needed (Bousquet et al 2001).

\section{Others}

The clinical expression of allergic disease has been reported in relation to other factors, such as changes in lifestyle, modification in diet, geographic variations, climate, socioeconomic conditions, family structure or history, infant feeding, excessive allergen exposure especially during early life, and cigarette smoking.

\section{Conclusion}

An increasing worldwide prevalence of allergic diseases such as allergic rhinitis and asthma has been observed over the last decades. The reasons for the increase of prevalence of these diseases are still incompletely understood. Many epidemiological studies have shown that environmental exposure to bacterial products (ie, endotoxin) may have a crucial role in the development of tolerance to ubiquitous allergens found in natural environments. Thus, the hygiene hypothesis becomes particularly attractive, since it is closely linked to modernization of lifestyles and improvement in living conditions. The future challenge is to understand the complex interplay between epidemiology and molecular genetics that have eventually caused sensitization and clinical manifestation of allergic diseases. It will have important implications for the development of new therapeutic strategies and prevention of allergic diseases.

\section{References}

Al-Mousawi MS, Lovel H, Behbehani N, et al. 2004. Asthma and sensitization in a community with low indoor allergen levels and low pet-keeping frequency. J Allergy Clin Immunol, 114:1389-94. 
Apter AJ, Gent JF, Frank ME. 1999. Fluctuating olfactory sensitivity and distorted odor perception in allergic rhinitis. Arch Otolaryngol Head Neck Surg, 125:1005-10.

Ashmore M. 1995. Human exposure to air pollutants. Clin Exp Allergy, 25(Suppl 3):12-22.

Baldini M, Lohman IC, Halonen M, et al. 1999. A polymorphism in the 5' flanking region of the $\mathrm{CD} 14$ gene is associated with circulating soluble CD14 levels and with total serum immunoglobulin E. Am J Respir Cell Mol Biol, 20:976-83.

Barnes KC, Neely JD, Duffy DL, et al. 1996. Linkage of asthma and total serum IgE concentration to markers on chromosome 12q: evidence from Afro-Caribbean and Caucasian populations. Genomics, 37: $41-50$.

Bener A, Mobayed H, Sattar HA, et al. 2004. Pets ownership: its effect on allergy and respiratory symptoms. Allerg Immunol (Paris), 36: $306-10$.

Bodner C, Godden D, Seaton A. 1998. Family size, childhood infections and atopic diseases. Thorax, 53:28-32.

Bousquet J, Van Cauwenberge P, Khaltaev N; Aria Workshop Group; World Health Organization. 2001. Allergic rhinitis and its impact on asthma. J Allergy Clin Immunol, 108(5 Supp1):S147-334.

Canonica GW, Holgate ST, Karlsson G, et al. 1998. The impact of allergic rhinitis on quality of life and other airway diseases-summary of a European conference. Allergy, 53(Suppl 41):7-31.

Carter PM, Peterson EL, Ownby DR, et al. 2003. Relationship of housedust mite allergen exposure in children's bedrooms in infancy to bronchial hyperresponsiveness and asthma diagnosis by age 6 to 7 . Ann Allergy Asthma Immunol, 90:41-4.

Cookson WO, Sharp PA, Faux JA, et al. 1989. Linkage between immunoglobulin $\mathrm{E}$ responses underlying asthma and rhinitis and chromosome 11q. Lancet, 1:1292-5.

Deichmann KA, Starke B, Schlenther S, et al. 1999. Linkage and association studies of atopy and the chromosome 11q13 region. J Med Genet, 36:379-82.

Devalia JL, Wang JH, Rusznak C, et al. 1994. Does air pollution enhance the human airway response to allergen? In vivo and in vitro evidence. ACI News, 6:80-4.

Durham SR, Ying S, Varney VA, et al. 1992. Cytokine messenger RNA expression for IL-3, IL-4, IL-5, and granulocyte/macrophage-colonystimulating factor in the nasal mucosa after local allergen provocation: relationship to tissue eosinophilia. J Immunol, 148:2390-4.

Eder W, von Mutius E. 2004. Hygiene hypothesis and endotoxin: what is the evidence? Curr Opin Allergy Clin Immunol, 4:113-17.

Edfors-Lubs ML. 1971. Allergy in 7000 twin pairs. Acta Allergol, 26: 249-85.

Fernandez-Caldas E, Lockey RF. 2004. Blomia tropicalis, a mite whose time has come. Allergy, 59:1161-4.

Gern JE, Weiss ST. 2000. Protection against atopic diseases by measlesa rash conclusion? JAMA, 283:394-5.

Hershey GKK, Friedrich MF, Esswein LA, et al. 1997. The association of atopy with a gain-of-function mutation in the $\alpha$ subunit of the IL-4 receptor. $N$ Engl J Med, 337:1720-5.

Hesselmar B, Aberg N, Aberg B, et al. 1999. Does early exposure to cat or dog protect against later allergy development? Clin Exp Allergy, 29:611-17.

Hoh J, Ott J. 2004. Genetic dissection of diseases: design and methods. Curr Opin Genet Dev, 14:229-32.

Hopp RJ, Bewtra AK, Watt GD, et al. 1984. Genetic analysis of allergic disease in twins. J Allergy Clin Immunol, 73:265-70.

Illi S, von Mutius E, Lau S, et al. 2001. Early childhood infectious diseases and the development of asthma up to school age: a birth cohort study. $B M J, 322: 390-5$.

International Rhinitis Management Working Group. 1994. International Consensus Report on Diagnosis and Management of Rhinitis. Allergy, 49(Suppl 19):1-34.

Jarvis D, Chinn S, Luczynska C, et al. 1997. The association of family size with atopy and atopic disease. Clin Exp Allergy, 27:240-5.
Johansson SGO, Bieber T, Dahl R, et al. 2004. Revised nomenclature for allergy for global use: Report of the Nomenclature Review Committee of the World Allergy Organization, October 2003. J Allergy Clin Immunol, 113:832-6.

Kabesch M, Tzotcheva I, Carr D, et al. 2003. A complete screening of the IL-4 gene: novel polymorphisms and their association with asthma and IgE in childhood. J Allergy Clin Immunol, 112:893-8.

Kawashima T, Noguchi E, Arinami T, et al. 1998. Linkage and association if an interleukin 4 gene polymorphism with atopic dermatitis in Japanese Families. J Med Genet, 35:502-4.

Krämer U, Heinrich J, Wijst M, et al. 1998. Age of entry to day nursery and allergy in later childhood. Lancet, 352:450-4.

Krishna MT, Mudway I, Kelly FJ, et al. 1995. Ozone, airways and allergic airways disease. Clin Exp Allergy, 25:1150-8.

Luczynska CM, Li Y, Chapman MD, et al. 1990. Airborne concentrations and particle size distribution of allergen derived from domestic cats (Felis domesticus). Measurements using cascade impactor, liquid impinger, and a two-site monoclonal antibody assay for Fel d I. Am Rev Respir Dis, 141:361-7.

Martinez FD, Holt PG. 1999. Role of microbial burden in aetiology of allergy and asthma. Lancet, 354(Suppl 2):SII12-15.

Matricardi PM, Rosmini F, Ferrigno L, et al. 1997. Cross-sectional retrospective study of prevalence of atopy among Italian military students with antibodies against hepatitis A virus. BMJ, 314:999-1003.

Matricardi PM, Rosmini F, Riondino S, et al. 2000. Exposure to foodborne and orofecal microbes versus airborne viruses in relation to atopy and allergic asthma: epidemiological study. $B M J, 320: 412-17$.

Marsh DG, Neely JD, Breazeale DR, et al. 1994. Linkage analysis of IL4 and other chromosome 5q31.1 markers and total serum immunoglobulin E concentrations. Science, 264:1152-6.

Michel O, Dentener M, Corazza F, et al. 2001. Healthy subjects express differences in clinical responses to inhaled lipopolysaccharide that are related with inflammation and with atopy. J Allergy Clin Immunol, 107:797-804

Michel O, Ginanni R, Duchateau J, et al. 1991. Domestic endotoxin exposure and clinical severity of asthma. Clin Exp Allergy, 21:441-8.

Moffatt MF, Cookson WO. 1999. Genetics of asthma and inflammation: the status. Curr Opin Immunol, 11:606-9.

Nishiyama C, Akizawa Y, Nishiyama M, et al. 2004. Polymorphisms in the Fc epsilon RI beta promoter region affecting transcription activity: a possible promoter-dependent mechanism for association between Fc epsilon RI beta and atopy. J Immunol, 173:6458-64.

Noguchi E, Shibasaki M, Arinami T, et al. 1997. Evidence for linkage between asthma/atopy in childhood and chromosome 5q31-q33 in a Japanese population. Am J Respir Crit Care Med, 156:1390-3.

Noguchi E, Shibasaki M, Arinami T, et al. 1998a. Association of asthma and the interleukin-4 promoter gene in Japanese. Clin Exp Allergy, 28:449-53.

Noguchi E, Shibasaki M, Arinami T, et al. 1998b. Evidence for linkage between the development of asthma in childhood and the T-cell receptor beta chain gene in Japanese. Genomics, 47:121-4.

Park BL, Kim LH, Choi YH, et al. 2004. Interleukin 3 (IL3) polymorphisms associated with decreased risk of asthma and atopy. J Hum Genet, 49:517-27.

Paunio M, Heinonen OP, Virtanen M, et al. 2000. Measles history and atopic diseases: a population-based cross-sectional study. JAMA, 283:343-6.

Peden DB. 2002. Influences on the development of allergy and asthma. Toxicology, 181-182:323-8.

Peterson EL, Ownby DR, Johnson CC. 2003. The relationship of housing and household characteristics to the indoor concentrations of Der $\mathrm{f} 1$, Der p 1, and Fel d 1 measured in dust and air samples. Ann Allergy Asthma Immunol, 90:564-71.

Pykalainen M, Kinos R, Valkonen S, et al. 2005. Association analysis of common variants of STAT6, GATA3, and STAT4 to asthma and high serum IgE phenotypes. J Allergy Clin Immunol, 115:80-7. 
Radon K, Windstetter D, Eckart J, et al. 2004. Farming exposure in childhood, exposure to markers of infections and the development of atopy in rural subjects. Clin Exp Allergy, 34:1178-83.

Riedl M, Diaz-Sanchez D. 2005. Biology of diesel exhaust effects on respiratory function. J Allergy Clin Immunol, 115:221-8.

Rosenwasser LJ, Klemm DJ, Dresback JK, et al. 1995. Promoter polymorphism in the chromosome 5 gene cluster in asthma and atopy. Clin Exp Allergy, 25(Suppl 2):74-8.

Sandin A, Bjorksten B, Braback L. 2004. Development of atopy and wheezing symptoms in relation to heredity and early pet keeping in a Swedish birth cohort. Pediatr Allergy Immunol, 15:316-22.

Schonberger HJ, Dompeling E, Knottnerus JA, et al. 2005. Prenatal exposure to mite and pet allergens and total serum IgE at birth in high-risk children. Pediatr Allergy Immunol, 16:27-31.

Sheikh A, Huwitz B. 2001. House dust mite avoidance measures for perennial allergic rhinitis. Cochrane Database Syst Rev, 4:CD001563.

Shek L, Tay A, Chew FT, et al. 2001. Genetic susceptibility to asthma and atopy among Chinese in Singapore-linkage to markers on chromosome 5q31-33. Allergy, 56:749-53.

Spector SL. 1997. Overview of comorbid associations of allergic rhinitis. J Allergy Clin Immunol, 99(Supp1):773-80.

Strachan DP. 1989. Hay fever, hygiene, and household size. BMJ, 299:1259-60.

Tan EC, Lee BW, Tay AWN, et al. 1999. Interleukin-4 receptor variant Q576R: ethnic differences and association with atopy. Clin Genet, 56:333-4.

Terreehorst I, Hak E, Oosting AJ, et al. 2003. Evaluation of impermeable covers for bedding in patients with allergic rhinitis. $N$ Engl $J$ Med, 349:237-46.

Toda M, Ono SJ. 2002. Genomics and proteomics of allergic disease. Immunology, 106:1-10.

Utell MJ, Samet JM. 1993. Particulate air pollution and health; new evidence on an old problem. Am Rev Respir Dis, 147:1334-5. van Strien RT, Engel R, Holst O, et al. 2004. Microbial exposure of rural school children, as assessed by levels of $\mathrm{N}$-acetyl-muramic acid in mattress dust, and its association with respiratory health. $J$ Allergy Clin Immunol, 113:860-7.

Varney VA, Jacobson MR, Sudderick RM, et al. 1992. Immunohistology of the nasal mucosa following allergen-induced rhinitis. Identification of activated T lymphocytes, eosinophils, and neutrophils. Am Rev Respir Dis, 146:170-6.

von Mutius E, Martinez FD, Fritsch C, et al. 1994a. Skin test reactivity and number of siblings. $B M J, 308: 692-5$.

von Mutius E, Martinez FD, Fritzsch C, et al. 1994b. Prevalence of asthma and atopy in two areas of West and East Germany. Am J Respir Crit Care Med, 149:358-64.

Wang DY, Chan A, Smith J. 2004. Management of allergic rhinitis: a common part of practice in primary care clinics. Allergy, 59:315-19.

Wang DY, Goh DYT, Ho AKL, et al. 2003. The upper and lower airway responses to nasal challenge with house dust mite Blomia tropicalis. Allergy, 58:78-82.

Wang D, Muhamad N, Smith D, et al. 2002. Rhinitis: do diagnostic criteria affect the prevalence and treatment. Allergy, 57:150-4.

Warner JA, Jones CA, Williams TJ, et al. 1998. Maternal programming in asthma and allergy. Clin Exp Allergy, 28(Suppl 5):35-8.

Wickens K, de Bruyne J, Calvo M, et al. 2004. The determinants of dust mite allergen and its relationship to the prevalence of symptoms of asthma in the Asia-Pacific region. Pediatr Allergy Immunol, 15: $55-61$.

Weidinger S, Klopp N, Wagenpfeil S, et al. 2004. Association of a STAT 6 haplotype with elevated serum IgE levels in a population based cohort of white adults. $J$ Med Genet, 41:658-63.

Wood RA, Chapman MD, Adkinson N Jr, et al. 1989. The effect of cat removal on allergen content in household-dust samples. J Allergy Clin Immunol, 83:730-4.

Zhang L, Chew FT, Soh SY, et al. 1997. Prevalence and distribution of indoor allergens in Singapore. Clin Exp Allergy, 27:876-85. 
